\title{
ESTUDIO DEL MICROCLIMA EN EL PROYECTO DE RESTAURACIÓN Y AJARDINAMIENTO DEL CLAUSTRO DE LA COLEGIATA DE SANTILLANA DEL MAR, EN CANTABRIA. ESPAÑA
}

\author{
(MICROCLIMATE STUDY IN THE RESTORATION AND GARCENING AT THE SANTILLANA \\ DEL MAR COLLEGIATE CHURCH CLOISER, IN CANTABRIA. SPAIN)
}

José Sancho Roda, Arquitecto

Instituto de Conservación y Restauración de Bienes Culturales.

128.38

Ministerio de Cultura

Fecha de recepción: 5-111-90

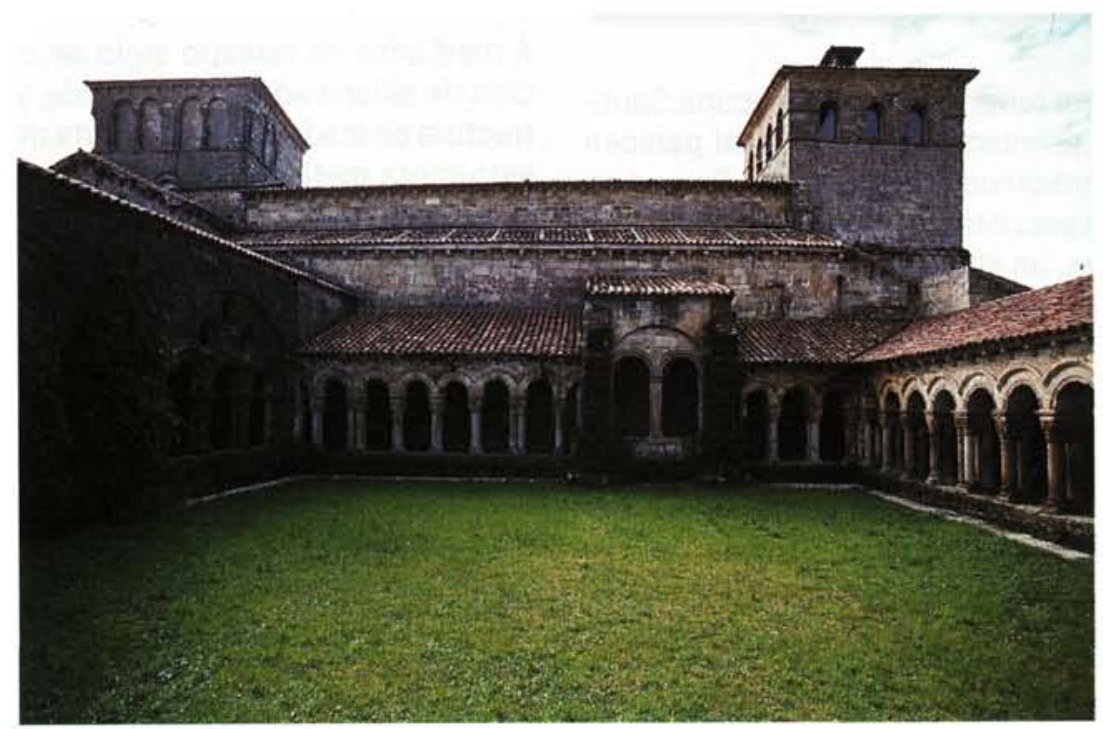

RESUMEN

Además de resolver los habituales problemas de conservación tales como cubiertas, drenajes etc., se ha buscado - por primera vez en España- una solución simultánea a los siguientes factores:

- reducir el deterioro de la piedra mediante la regulación natural de la humedad que proporcionan las plantas.

- recuperación de la imagen perdida y un aspecto del Claustro mucho más vital, porque los arbustos, plantas y flores son elementos vivos.

- reencuentro con una función cultural desaparecida.

\section{SUMMARY}

Moreover of resolving usual problems of conservation as covering, drainage, etc. it has been searched -first time in Spain - a simultaneons answer to the next points: to reduce the damage of stone by means of virtue of natural regulation of moisture that plants furnish.

- To recover the lost image and a cloister look much more vital, bushes and plants are living beings.

- To found again a missing cultural function. 


\section{RESEÑA HISTÓRICA DE LA VILLA DE SANTILLANA DEL MAR}

Santillana del Mar es una conocida población de Cantabria en la que la topografía del terreno le da ventajas considerables. Unas leves colinas la separan del mar y le proporcionan agua abundante, al tiempo que protegen del viento norte.

Las Cuevas de Altamira nos determinan que la zona estuvo habitada por el hombre al menos desde hace unos catorce mil años.

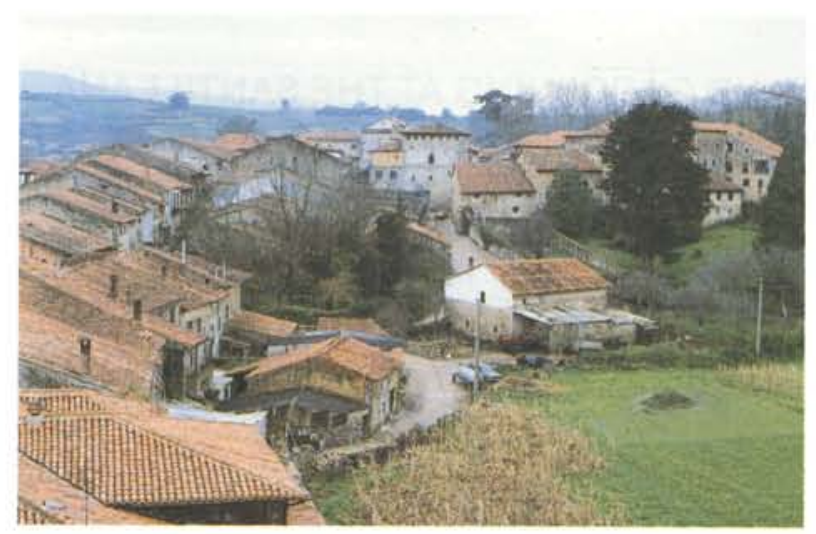

Es probable que en el terreno que ahora ocupa SantiIlana hubiera algún asentamiento celta y asi parecen indicarlo vestigios próximos a la población. En una ermita cercana hemos encontrado hace poco, oculto por otras construcciones, un altar cristiano a base de una estela romana a la que se le habia practicado una oquedad que guardaba una caja con reliquias, siendo el altar más antiguo del noroeste de España y coetáneo con los que se conservan en algunas iglesias prerrománicas de Cataluña. El caserío tuvo su principal desarroIlo a partir del siglo XII y su apogeo en los siglos XVI y XVII. El conjunto está bastante bien conservado, hay pocos pastiches aunque el entorno se ha degradado bastante con las nuevas edificaciones.

\section{DATOS HISTÓRICOS SOBRE LA COLEGIATA}

El documento más antiguo, del que se conserva copia en la Colegiata, data del 817.

Antes de esa fecha existe la tradición de que hubo un monasterio visigodo, fundado por la casa de Lara, relacionada con la Casa Real de Castilla, que a partir de entonces distinguió a la Colegiata con sus donaciones y privilegios.

No se conoce la Orden que se hizo cargo del Monasterio en época primitiva, pero en el siglo X tenía Abad y monjes que no eran benedictinos.

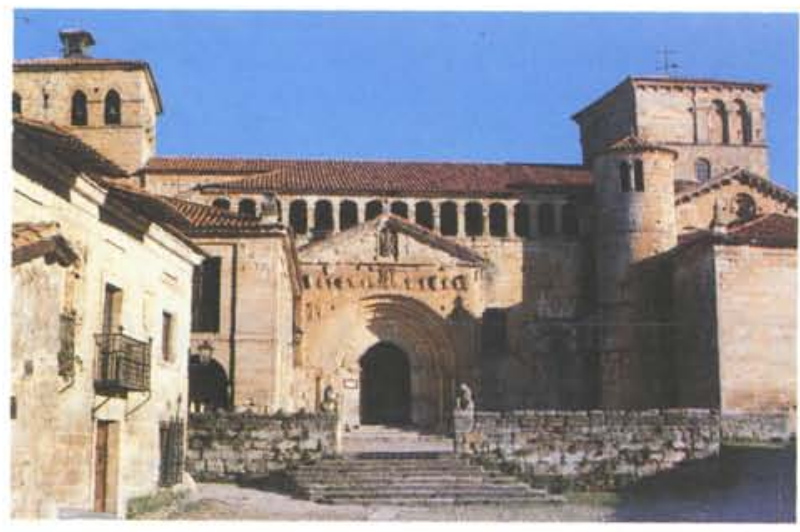

En cuanto a vestigios arquitectónicos, no se han encontrado de época anterior al siglo XI.

A partir del año 1196 dejó de existir como Monasterio y se transformó en Cabildo.

La estructura fundamental del Claustro y de la Iglesia es románica, del siglo XII.

En la fachada principal se hizo una gran reforma en el siglo XVII, utilizando como adorno algunos relieves de la construcción románica.

A mediados de nuestro siglo se eliminó una edificación de sillería adosada al ábside, y se sustituyó la estructura de madera de la cubierta de la nave central por estructura metálica.

\section{EL CLAUSTRO DE LA COLEGIATA, RESTAURACIONES ANTIGUAS}

El primitivo Claustro del siglo XII fue transformado en los siglos XIV y XV para la formación de capillas, y el ala noroeste, en el siglo XIX, se transformó en una galeria con arcos que doblan en dimensiones a las otras tres.

El arquitecto, Juan Bautista Lázaro, a finales del siglo pasado, realizó una importante obra de restauración.

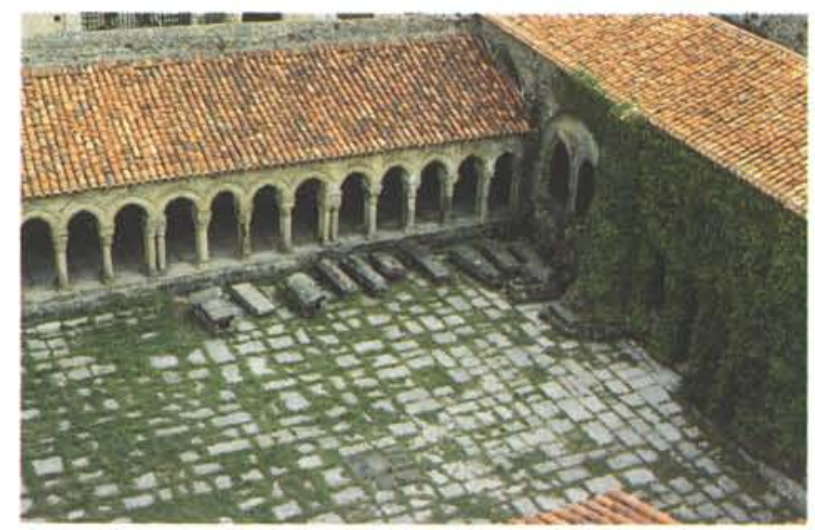

http://informesdelaconstruccion.revistas.csic.es 
Comparando las fotografías antiguas con el estado actual sabemos que desmontó casi toda la sillería del Claustro, ya que no coinciden los aparejos de la piedra en las enjutas de los arcos y corrigió el desplome.

Rehizo las cubiertas del Claustro y colocó un entrevigado con madera de castaño y de roble.

A finales de siglo, también se realizó el vaciado del espacio abierto del Claustro retirando las tumbas y dejando los restos en una sala de la galería suroeste que después se tapió.

Se construyeron galerías de drenaje siguiendo las diagonales del Claustro, se rellenó otra vez de tierra y se colocó el enlosado que ha permanecido hasta 1980. Varias tapas de piedra y tres sarcófagos se colocaron al aire libre, en uno de los ángulos del Claustro.

\section{AGRIETAMIENTOS EN LAS CUBIERTAS DEBIDO AL SISTEMA ANTIGUO DE RESTAURACIÓN}

Las cubiertas, rehechas a finales del siglo XIX, se han repasado en varias ocasiones. Al levantar la teja encontramos una capa de compresión agrietada por completo, sobre una tela asfáltica ya acartonada y también agrietada sobre tabla de pino y resto de estructura también de pino. La capa de compresión no llevaba armadura. La madera estaba descompuesta según zonas.

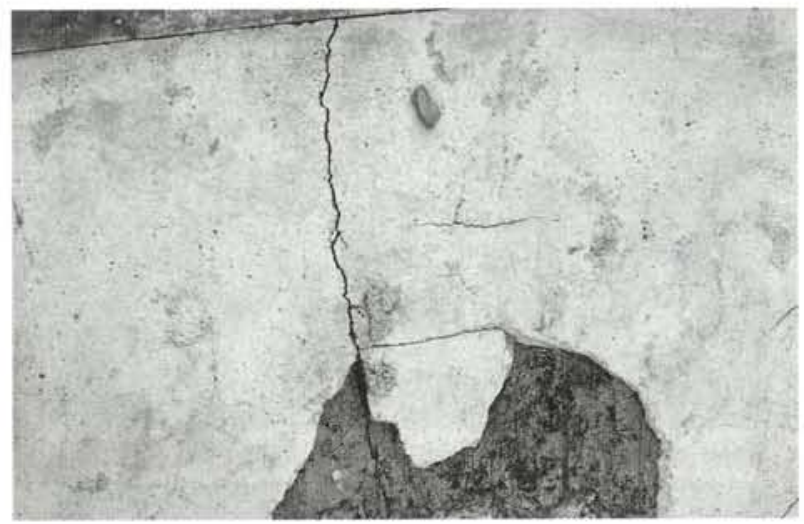

Indudablemente la madera, que es un elemento vivo, había agrietado la capa de compresión y por las grietas penetraba el agua que motivó la pudrición por hongos de la madera, más o menos según tenía acceso la humedad.

El agua en algunos puntos circulaba por debajo de la cubierta y empapaba los muros de piedra de los ángulos del Claustro y las cornisas, cimacios, capiteles y columnas de las galerías románicas, acelerando el deterioro de la piedra.

\section{FACTORES DEL DETERIORO EN LA PIEDRA DEL CLAUSTRO}

Además de las filtraciones de agua por las caras anterior y posterior de los soportales del Claustro, comprobamos que también actuaba directamente en los capiteles y columnas el agua de Iluvia.

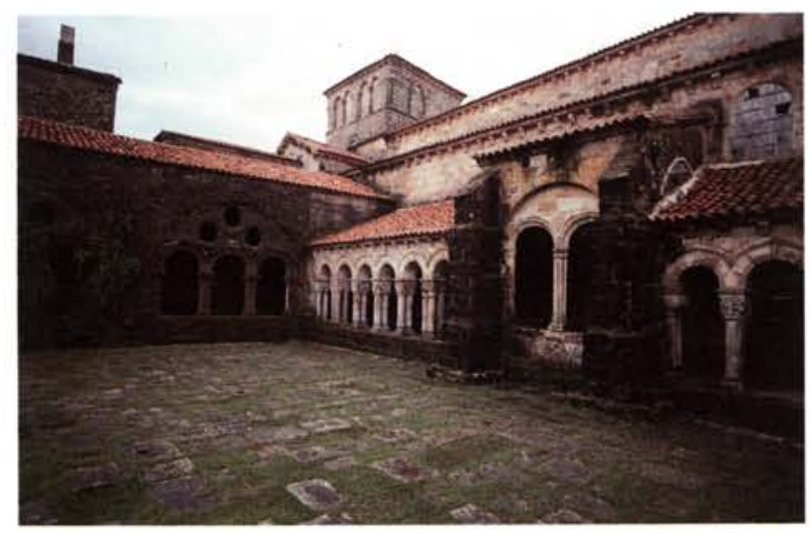

Por las mediciones climáticas efectuadas se comprobó también que actuaba intensamente el aire húmedo procedente del mar. A esa humedad ambiental contribuía, en buen grado, el agua almacenada en el subsuelo.

Mientras tanto la piedra arenisca utilizada había aguantado bastante bien el paso de los años, si bien tenemos constancia gráfica de que al menos en el siglo XIX ya hubo necesidad de reponer varios fustes y otros elementos arquitectónicos.

El resultado de todas estas agresiones era variado: proliferación de daños bióticos por un lado, y por otro ero. sión y descomposición de la piedra.

En orden de prioridades consideramos más urgente el drenaje, luego las cubiertas y, por último, la mejora del microclima con un ajardinamiento.

\section{SISTEMAS ANTIGUOS DE DRENAJE}

En 1894 se habían realizado obras importantes de drenaje que, con el tiempo, se habían saturado y no cum. plian su misión.

Por otra parte ese drenaje quedó incompleto en la galeria medianera con la Colegiata, que es precisamente la zona que embalsaba más agua por recoger el agua de la mitad de cubiertas de toda la Colegiata.

El drenaje estaba constituido por zanjas cubiertas con losas de piedra. Sobre ese nivel se cubrió con más lo. sas todo el recinto interior del Claustro. El hecho de 


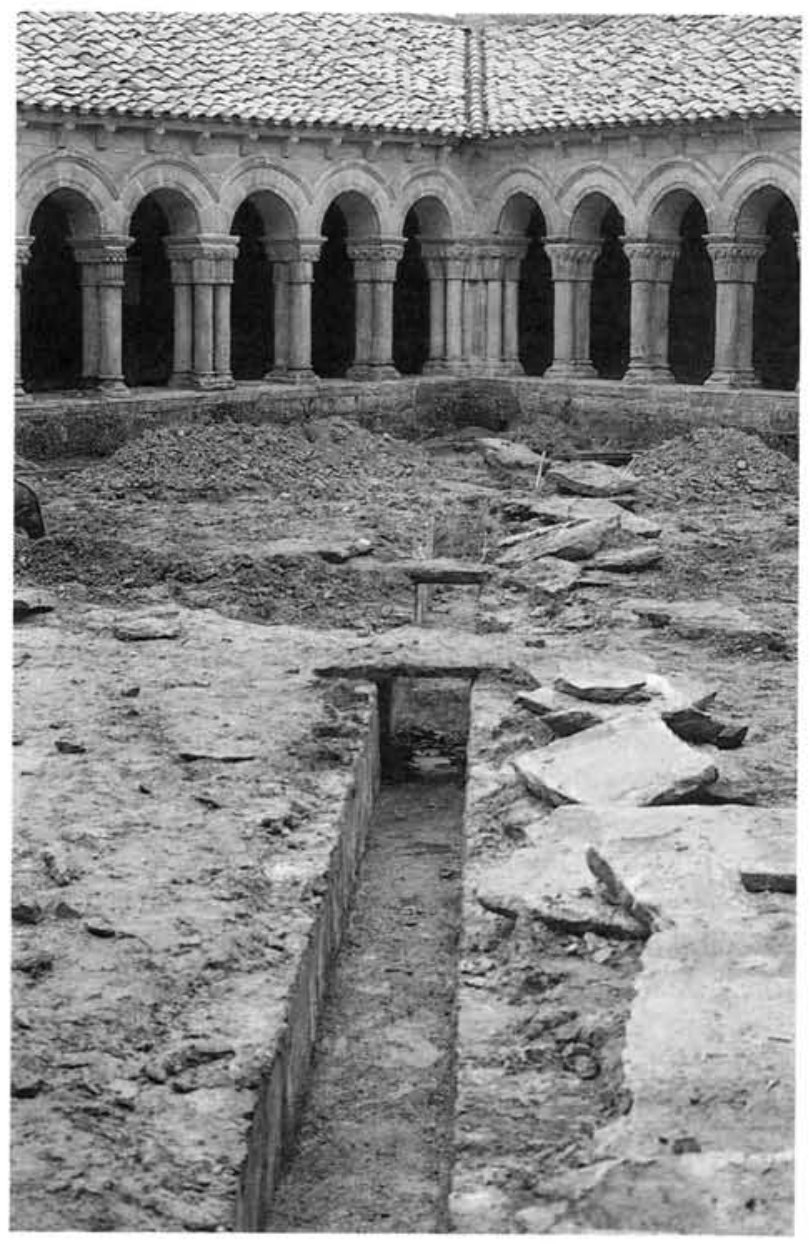

tener estas canalizaciones casi al nivel normal del terreno perjudicaba y dificultaba el futuro ajardinamiento, pero no nos pareció oportuno destruirlas porque podian cumplir aún su misión.

En uno de los ángulos apareció una grieta natural en la roca que aflora en algunos puntos. Desescombramos la grieta y encontramos una fisura estrecha por donde pudimos bajar y averiguar que a seis metros de profundidad existía el lecho en roca de un riachuelo que pasa por debajo de toda la Colegiata y es, tal vez, el causante de sus deformaciones estructurales por asientos de la cimentación.

\section{GRABADOS INÉDITOS DEL CLAUSTRO}

Todas estas intervenciones no eran fruto de la improvisación. Desde 1977 fuimos analizando y valorando los factores del deterioro.

Para ello fue de gran utilidad la búsqueda y recopilación de documentación antigua que pudiera servirnos de medio comparativo. Encontramos, por ejemplo, estos grabados inéditos desde que se publicaron en 1885 , en "Revista Popular", que son los más antiguos encontrados hasta ahora referidos al Claustro.

Se ve todo el interior del Claustro recrecido, con hierbas de todo tipo y un ciprés precisamente en el lugar donde existe la grieta natural.
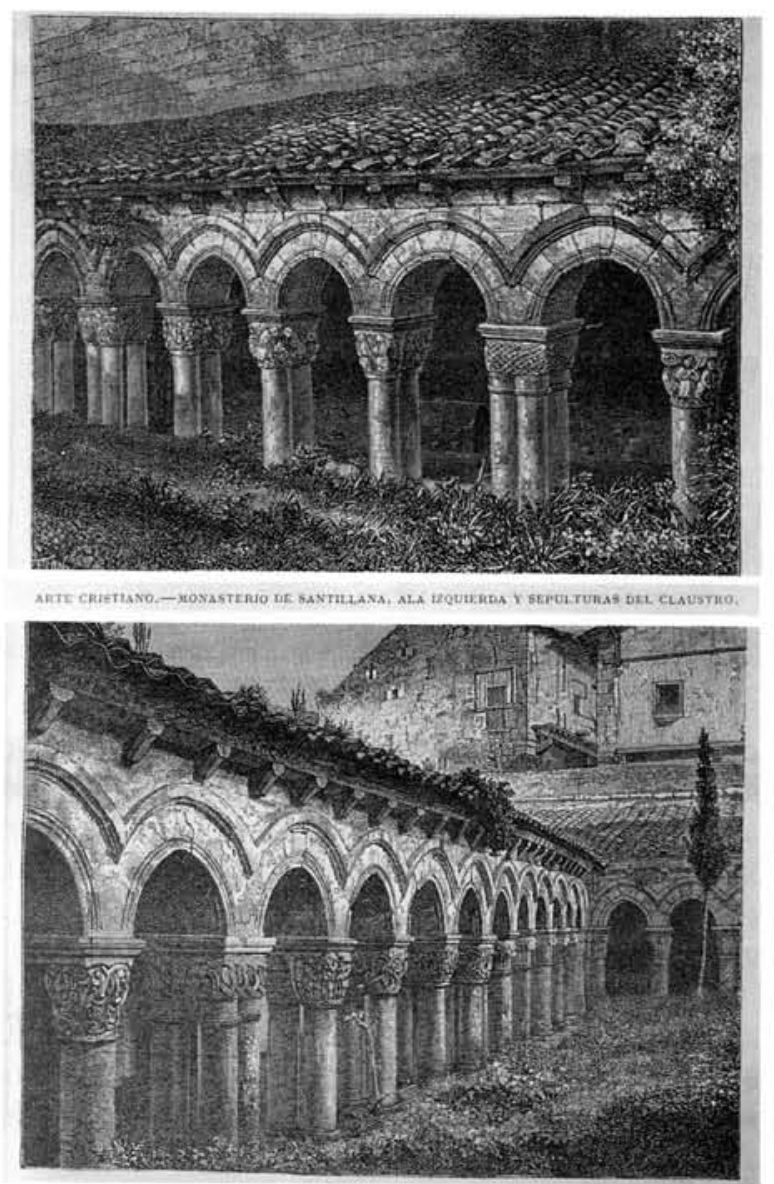

http://informesdelaconstruccion.revistas.csic.es 


\section{FOTOGRAFIAS DEL SIGLO XIX}

Por fotografías de finales del siglo XIX averiguamos detalles más importantes. La cubierta de teja está sobreelevada con respecto a la cornisa, probablemente sobre una fila de lajas de piedra natural que en 1894 desaparecieron.

Las galerias están desplomadas hacia el interior - lo que llevaria después a su reconstrucción-, y algunas columnas están seriamente dañadas por la erosión, lo que hace necesario el apuntalamiento.

Las enjutas de los arcos tienen un aparejo determinado, que no coincide con el actual, y el reparto de canecillos también ha variado.

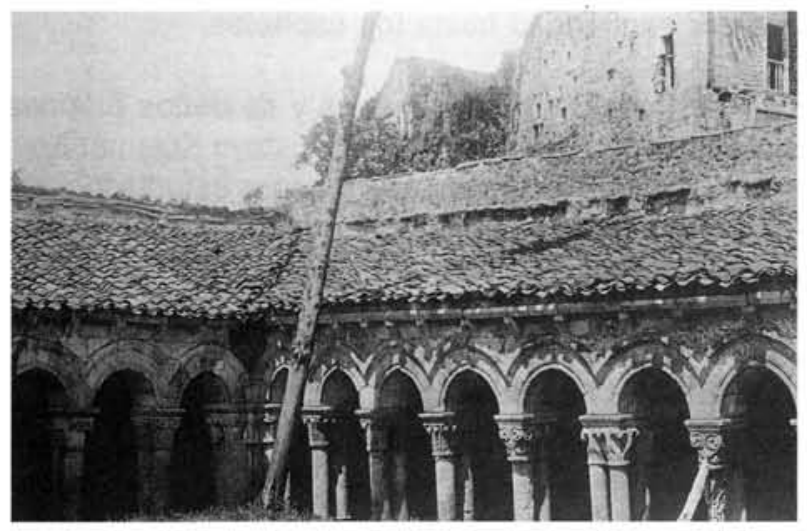

Todo ello, junto con la ausencia de desplome, nos hace suponer que el Claustro fue desmontado, casi en su totalidad, a finales del XIX y vuelto a montar sustituyendo elementos dañados.

La piedra utilizada en la restauración se volvió a coger de las mismas canteras, pero no se seleccionó demasiado y al cabo de un siglo han vuelto a deteriorarse.

\section{DAÑOS PRODUCIDOS POR EROSIÓN DEBIDO AL AGUA Y A LA HUMEDAD AMBIENTAL}

Algunos capiteles y columnas orientadas al interior del Claustro presentan ampollas y descomposición del mortero bastardo.

Donde no hubo caída de agua no se aprecia tanto el deterioro. Fácilmente comprobable porque son capiteles dobles en un solo bloque de piedra.

La humedad ambiental también ha contribuido al desgaste, pero en mucho menor grado.

Los daños bióticos tampoco afectaron demasiado aquí, debido precisamente a la dificultad de permanencia ante el azote continuo del agua.

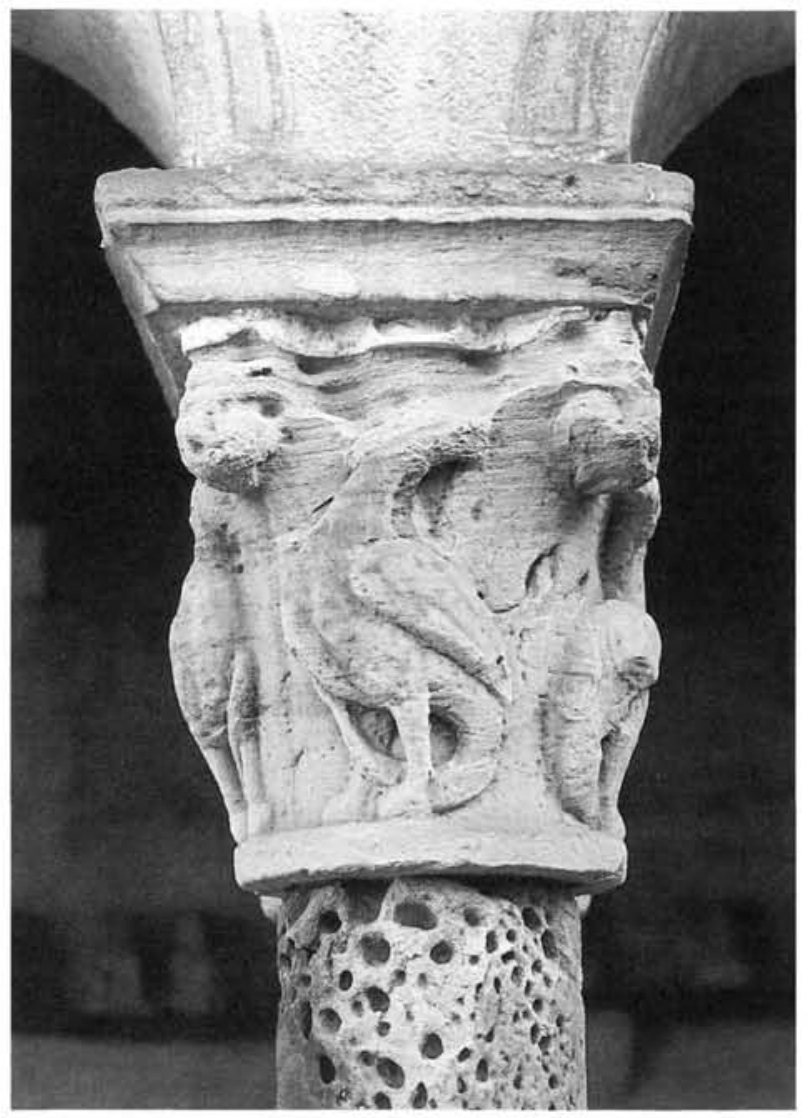

http://informesdelaconstruccion.revistas.csic.es 
La piedra utilizada es arenisca de buena calidad, salvo la variedad gris. Hicimos pruebas de absorción y porosidad y comprobamos que era adecuada la proporción de feldespatos que son importantes para la calidad de una piedra arenisca.

En la unión de capitel y cimacio se observa descomposición del mortero bastardo.

Las ampollas y la rotura en placas se deben a cambios bruscos de humedad que producen retracciones por secado con separación de placas.

Estas capas están relacionadas con las vetas de cedimiento, fenómeno fácilmente identificable por microanálisis.

\section{EROSIÓN POR ACCIÓN DIRECTA DEL AGUA $Y$ OTROS FACTORES}

En este caso también el deterioro se debe a la acción directa del agua. La columna repuesta en el siglo pasado, en color grisáceo, es de peor calidad. En este tipo de piedras existen sustancias aceitosas naturales procedentes de animales marinos pequeños, que resisten mal a la acidez actual del agua de lluvia, desarmándose también en placas.

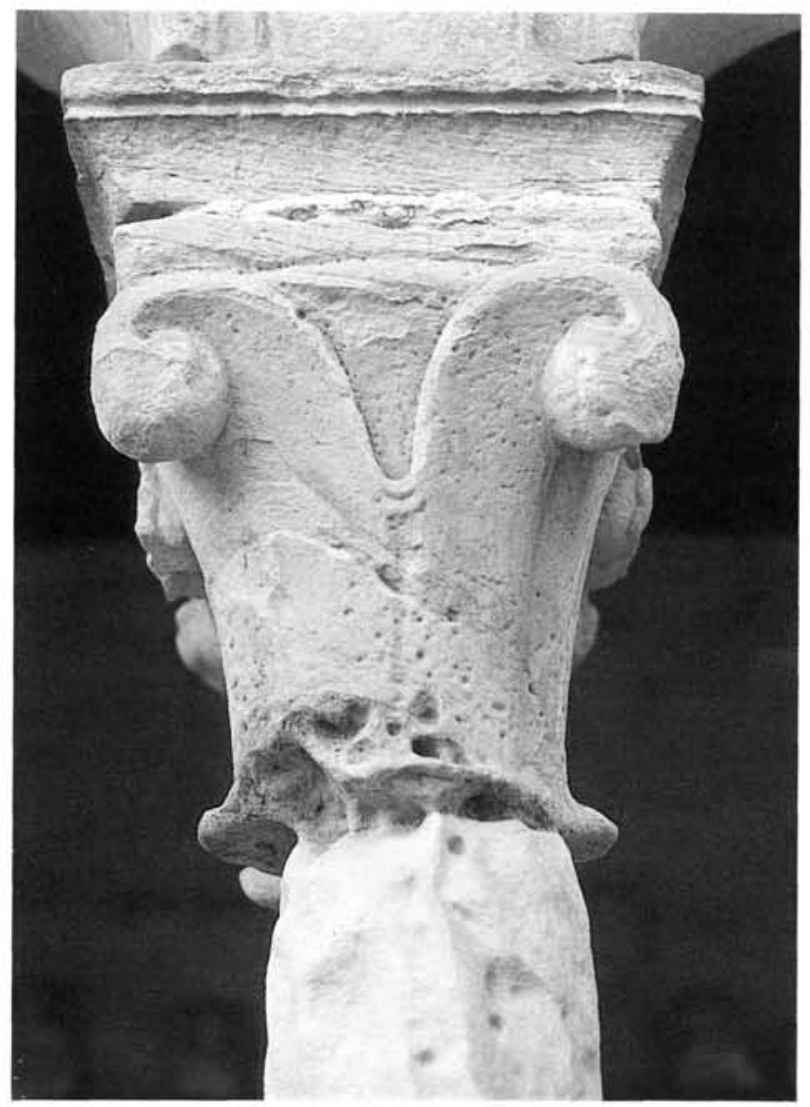

(C) Consejo Superior de Investigaciones Científicas Licencia Creative Commons 3.0 España (by-nc)
La dovela inferior del arco que apoya en el cimacio tiene rotos los ángulos que se orientan al interior del Claustro, debido a la compresión que produjo el desplome, ahora ya corregido. Este desmontaje de 1894 no revistió peligro de nuevas roturas de compresión debido al cambio en el reparto de cargas, ya que tanto las basas, como columnas, capiteles y cimacios son de sobra resistentes para el peso de la cubierta.

Sin embargo en otros sitios puede ser gravemente peligroso. Por ejemplo, en el Monasterio de Silos se desmontaron hace pocos años varios capiteles con el fin de darles un tratamiento a base de resinas. Dejando aparte el motivo del desmontaje que es muy discutible, el problema es que al montarlos de nuevo variaron lógicamente los repartos de las cargas y como en ese caso tienen poca masa de piedra en proporción al gran peso que soportan, se están produciendo nuevas roturas de compresión.

\section{EFECTOS DE MECHA DEBIDOS A DAÑOS BIÓTICOS}

Hasta finales del siglo XIX todo el Claustro estaba rellenado de tierra en contacto con las columnas, por lo que es evidente que se producia un proceso de humedad por capilaridad hasta los capiteles.

La investigación microclimática y de daños bióticos realizada por el Doctor Biólogo Gustavo Kraemer Koeller ha sido muy detallada. Los musgos estudiados proliferan también en las juntas entre los diferentes elementos arquitectónicos.

Ante problemas de este tipo caben varias soluciones. Descartamos las que suponen desmontaje por los problemas aludidos.

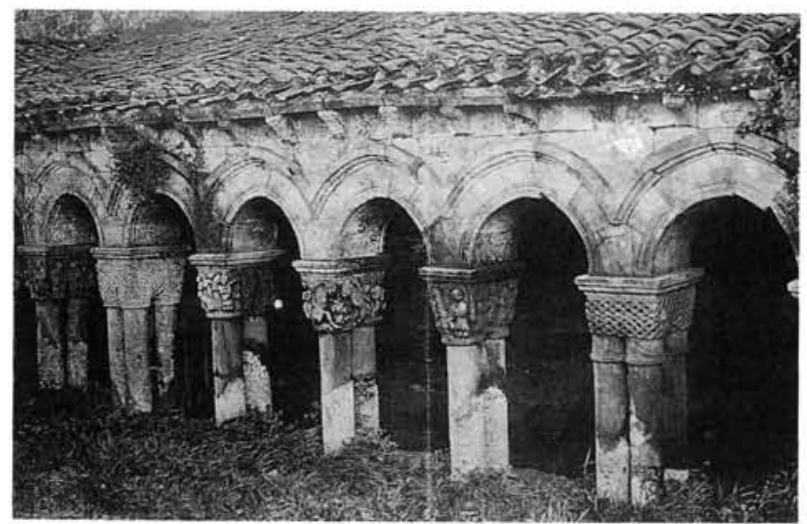

http://informesdelaconstruccion.revistas.csic.es 
Existen también sierras especiales que podrian cortar las juntas para introducir después materiales aislantes, pero esto produce vibraciones y podría dañar las piedras además de producir ligeros asientos aunque se haya hecho un buen apuntalamiento.

Pensamos que en todo caso, si se considera imprescindible, pueden limpiarse hasta una cierta profundidad las juntas e introducir algún material inerte que se estudiaría en cada caso, y así cortar el efecto de mecha.

\section{LA INVESTIGACIÓN PLURIDISCIPLINAR}

Por la complejidad de los problemas se llega a la conclusión de que es imprescindible el trabajo en equipo. Ningún profesional aislado debe considerarse capacitado para resolver él solo todos los problemas.

En Santillana del Mar ha sido fundamental la intervención del biólogo citado, ya que los daños bióticos te-

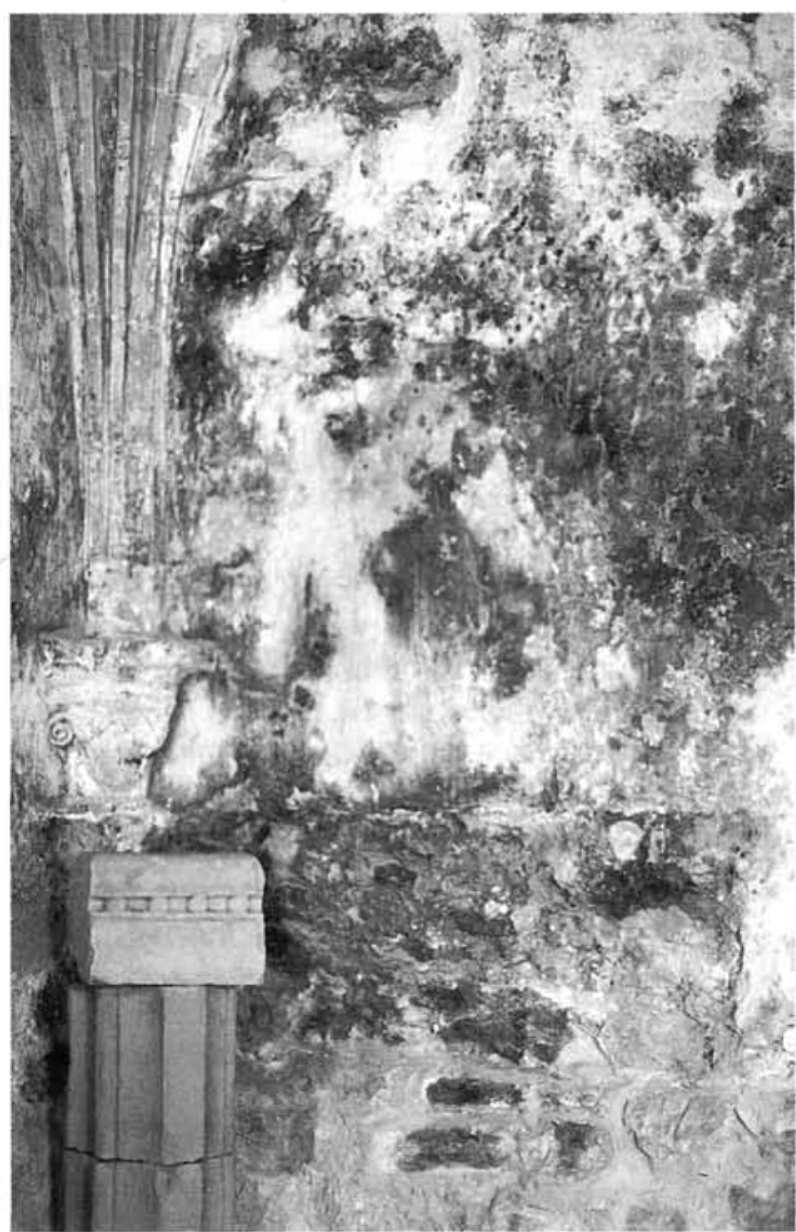

(C) Consejo Superior de Investigaciones Científicas Licencia Creative Commons 3.0 España (by-nc) nían especial importancia. También intervino en la excavación arqueológica del Claustro el Arqueólogo don Miguel Angel Garcia Guinea para la zona en que debía completarse el drenaje. Se contó también con la colaboración del Servicio de Meteorología de Santander que facilitó datos importantes sobre el microclima de Santillana. Se hicieron asimismo análisis y comprobaciones de las condiciones de la piedra del Claustro y desde luego se manejó toda la documentación gráfica posible: grabados, fotografías antiguas, proyectos antiguos de restauración del Archivo Central de Alcalá de Henares y bibliografía completa. Luego, para el ajardinamiento, cambiamos impresiones con profesionales muy competentes.

Ante este sector de una de las paredes del Claustro, tal como estaba hasta hace poco, no cabe duda que se plantean cuestiones tan variadas como origen del daño, tipo de agresión biótica, forma de eliminación sin alterar condiciones de los materiales pétreos o revocos, forma de evitar la reproducción del daño, forma de restaurar el revoco o la piedra dañada y las juntas, etcétera.

\section{EXPOSICIÓN PÚBLICA DE CARÁCTER DIDÁCTICO EN EL MISMO MONUMENTO}

Una buena costumbre de diversos paises europeos, que en España no se sigue sistemáticamente, consiste en informar a la población del tipo de obras que se van a llevar a cabo en los monumentos importantes, indicando técnicos, empresas, presupuestos y sobre todo planos, dibujos o fotos de lo que se pretende restaurar.

En el mismo Claustro hicimos una exposición y descripción de los problemas que habiamos encontrado y la forma en que ibamos a solucionarlos. Naturalmente ya habian intervenido los mecanismos normales de control de proyectos, pero a raíz de estas explicaciones surgió por ejemplo la colaboración de dos vecinos que poseían negativos de fotografías inéditas del siglo pasado que fueron muy útiles para nosotros.

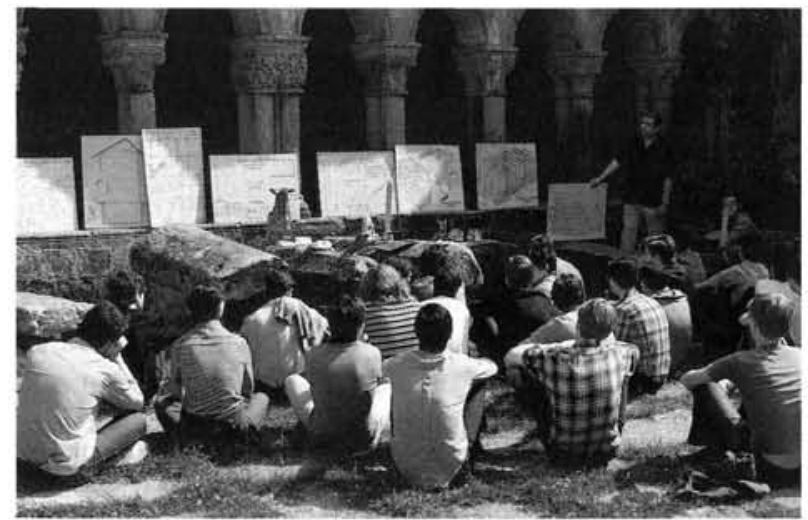

http://informesdelaconstruccion.revistas.csic.es 


\section{CURVAS CLIMÁTICAS EN CAPITELES, COLUMNAS Y CIMIENTOS}

Comprobaciones directas efectuadas por nosotros permitieron comprobar que la humedad relativa del aire dominaba completamente el microclima de los capiteles, especialmente cuando se producía viento de componente noroeste.

La consecuencia es que la humedad por capilaridad era de mucha menos importancia en este caso, incluso a pesar de no tener aún resuelto el problema de drenaje por lo que se rechazaba, con seguridad, cualquier so. lución de desmontaje u otros medios traumáticos para cortar la humedad ascendente.

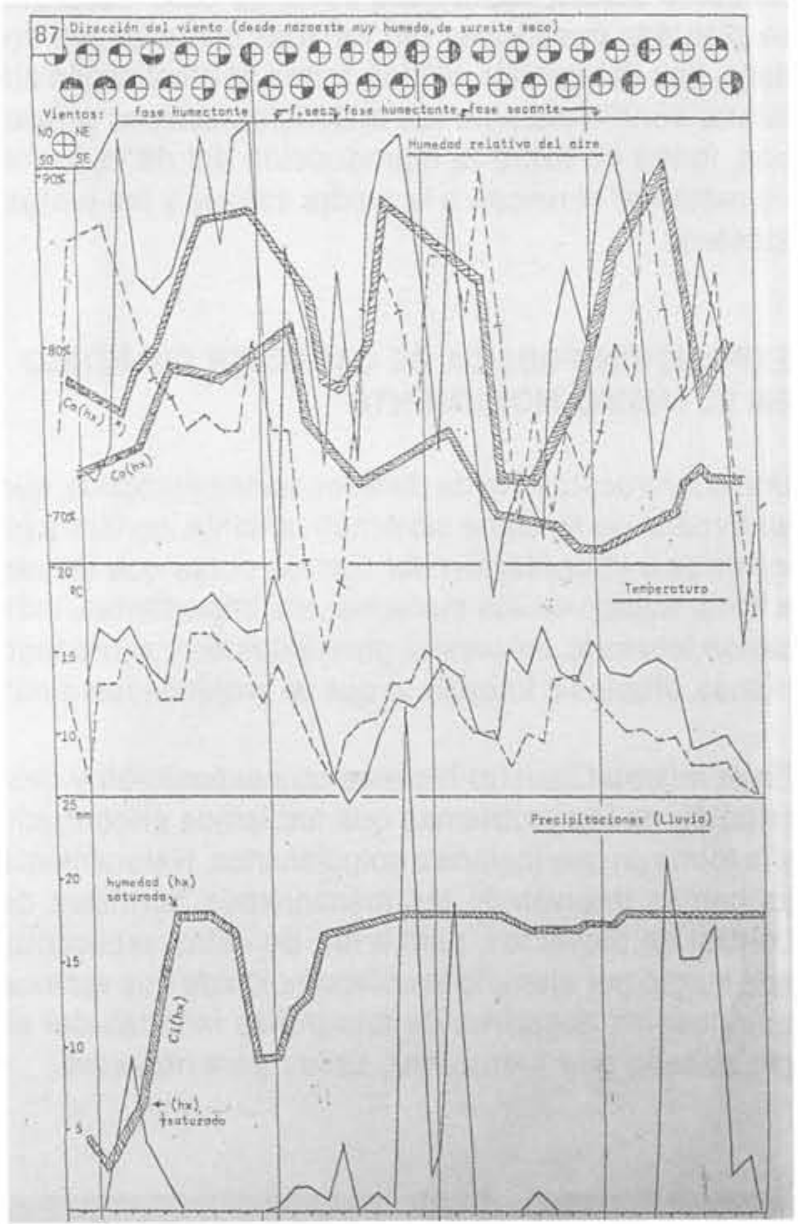

G. Kraemer

\section{LIMPIEZA EN SECO DE LA SUCIEDAD}

Aquí, por el tipo de suciedad acumulada en la piedra, era apropiado utilizar simplemente cepillos pequeños de tipo blando, y compresor de aire convenientemente regulado. Durante un tiempo se redujo tan sólo la acción del aire húmedo procedente del mar y la proliferación de los daños bióticos.

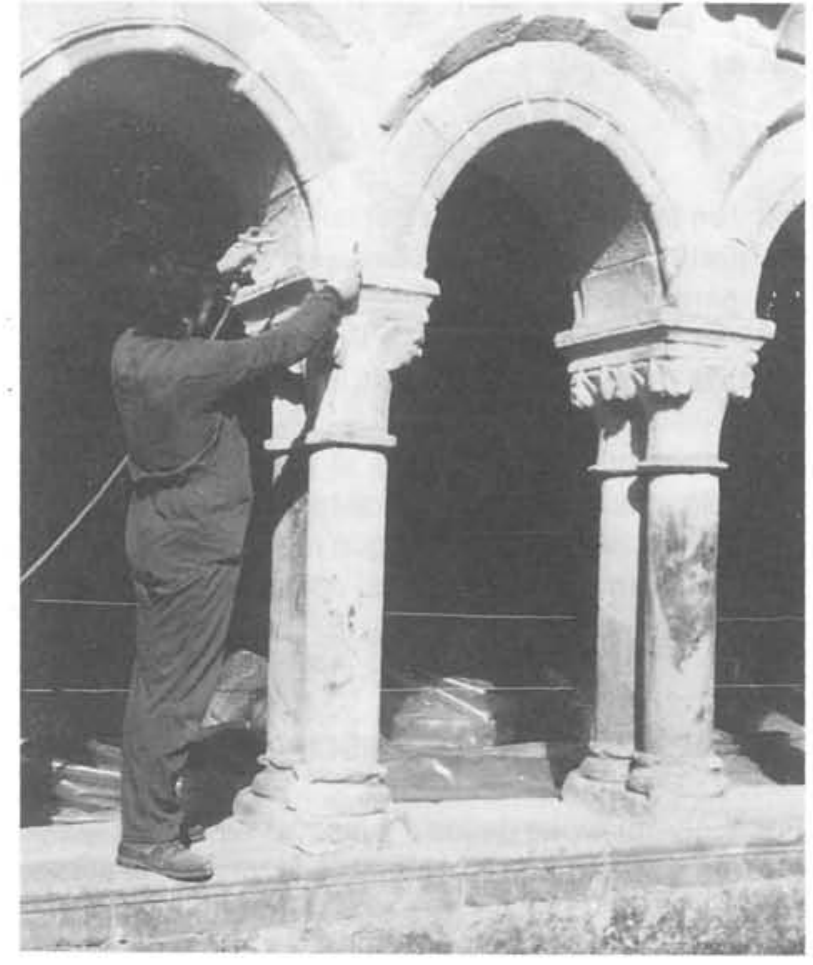

Para ello se aplicó un germicida inocuo para la piedra (el mismo que utiliza la Fábrica Nacional de Moneda para el tratamiento del papel), según fórmula e investigación del Dr. Kraemer.

Lo difícil, en este aspecto, es no tanto la limpieza de los daños bióticos sino lograr que no vuelvan a repro. ducirse.

Esta actuación protegió -exclusivamente de daños bióticos - la piedra en los tres años en que se demoró la restauración. No impidió, naturalmente, que en uno de los ángulos del Claustro, en el que el agua tenía una entrada importante, continuara la degradación de la piedra.

\section{DETALLE DE LOS MUSGOS HEPATITICOS}

Con este detalle del tipo de musgos que se reproducian en Santillana sólo pretendia resaltar, una vez más, lo que ya empieza a saberse: No existe un mal de piedra. No es un simple problema químico. No es sólo un proceso normal de erosión de piedra que podría estudiar un geólogo con todo detalle, es un problema complejo y distinto en cada caso.

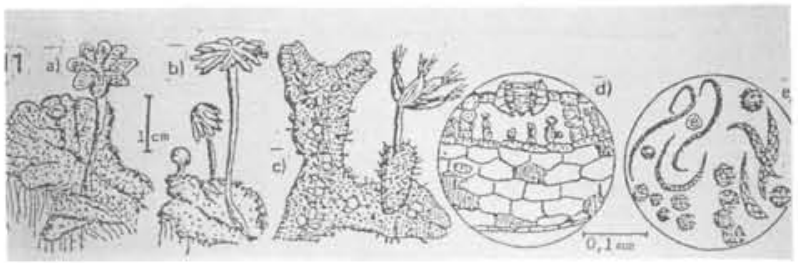




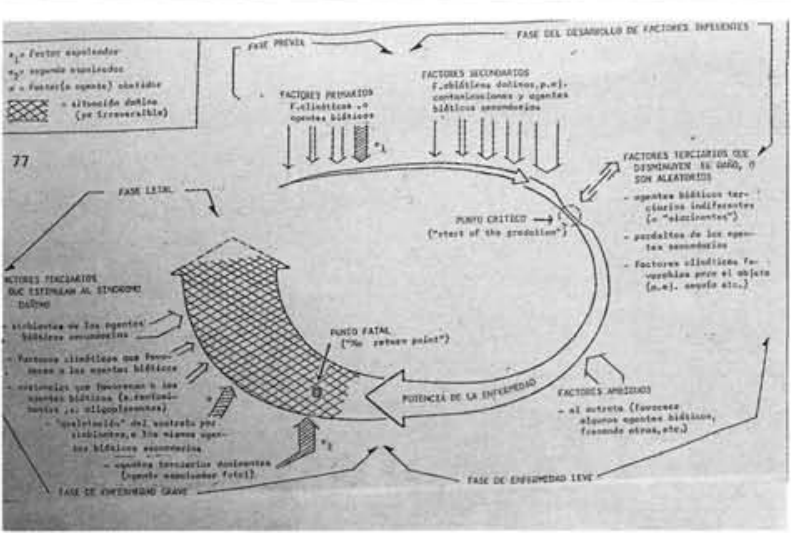

Esquema de una enfermedad biótica. - El gráfico resalta hasta qué punto los factores climáticos estimulan los daños bióticos. (Kraemer, publicación en prensa).

El desarrollo inicial negativo puede ser parado antes de entrar en la fase grave. Alli, al intervenir factores estimulantes, se llega a un punto fatal en el que no hay posibilidad de retorno porque la destrucción ya está hecha.

G. Kraemer

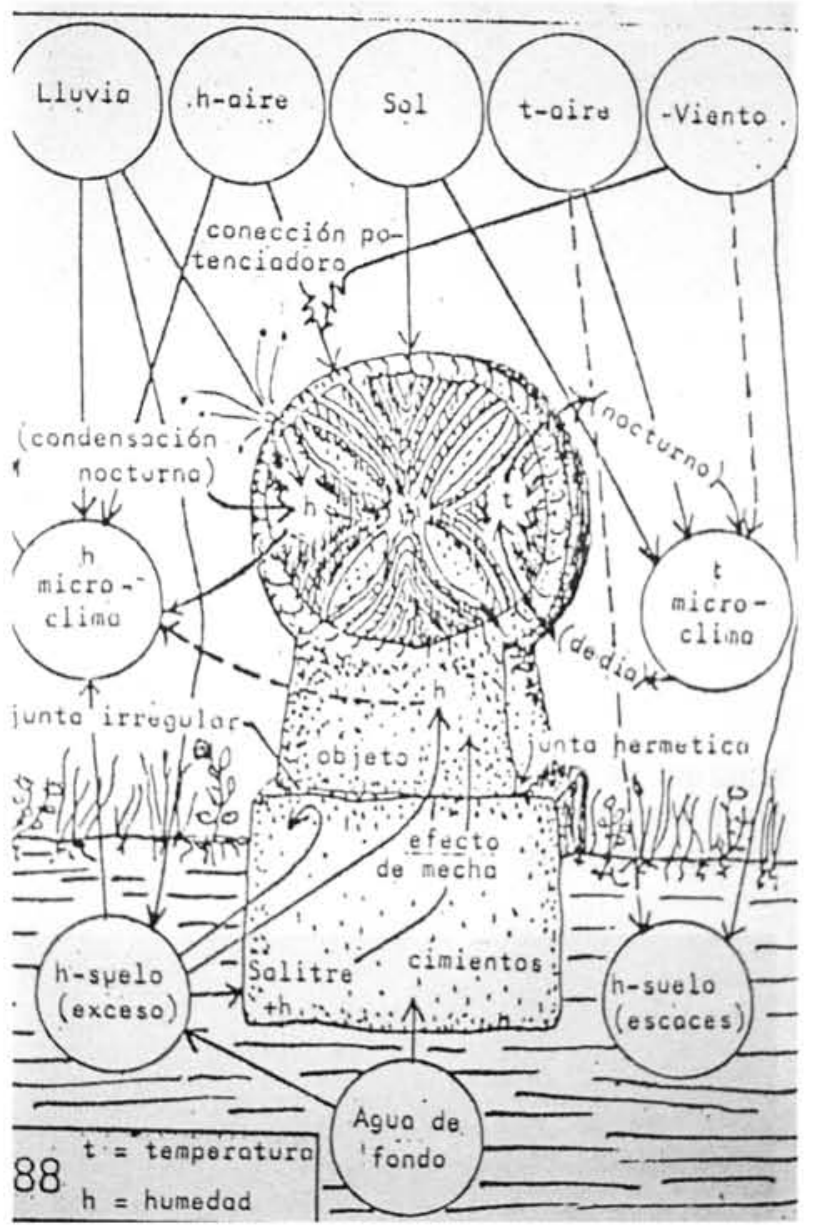

Esquema de factores microclimáticos. - En este esquema teórico, re. ferido a una estela de piedra clavada en el suelo, se resumen algunos de los diferentes factores que intervienen en el microclima de forma habitual.

En la zona superior, y a nivel del suelo, se acentúa el efecto de los factores climáticos que actúan de diferente forma durante el dia y la noche.

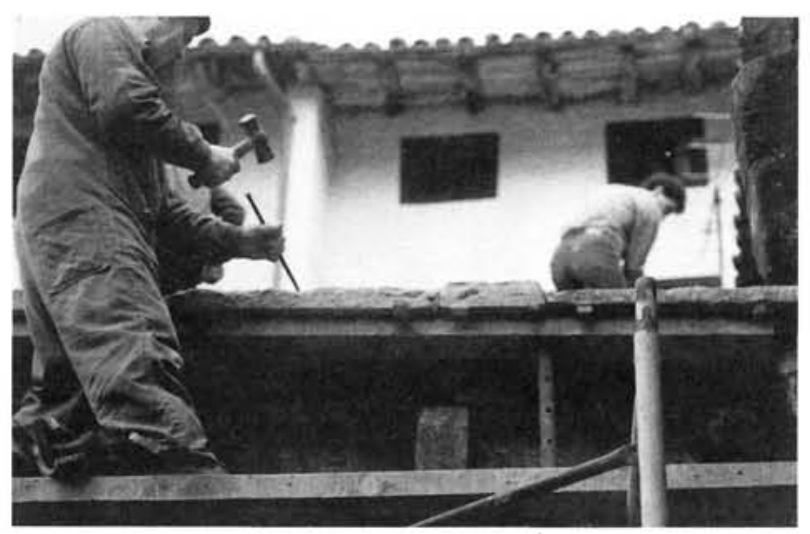

Voladizo de la cornisa. - En las fotos y grabados antiguos vimos que sobre la cornisa hubo un recrecido también de piedra, que se elimino en el siglo XIX.

No sabemos si lo tuvo también en su origen, pero hemos comprobado que existe en otros aleros de la Colegiata, por lo que se ha proce. dido a su instalación sobrevolando ligeramente la cornisa para pro. teger del agua de lluvia.

Por las herramientas utilizadas en la labra de la piedra, y por toda la documentación gráfica, cualquier investigador del futuro podrá cons. tatar que corresponde a nuestros dias.

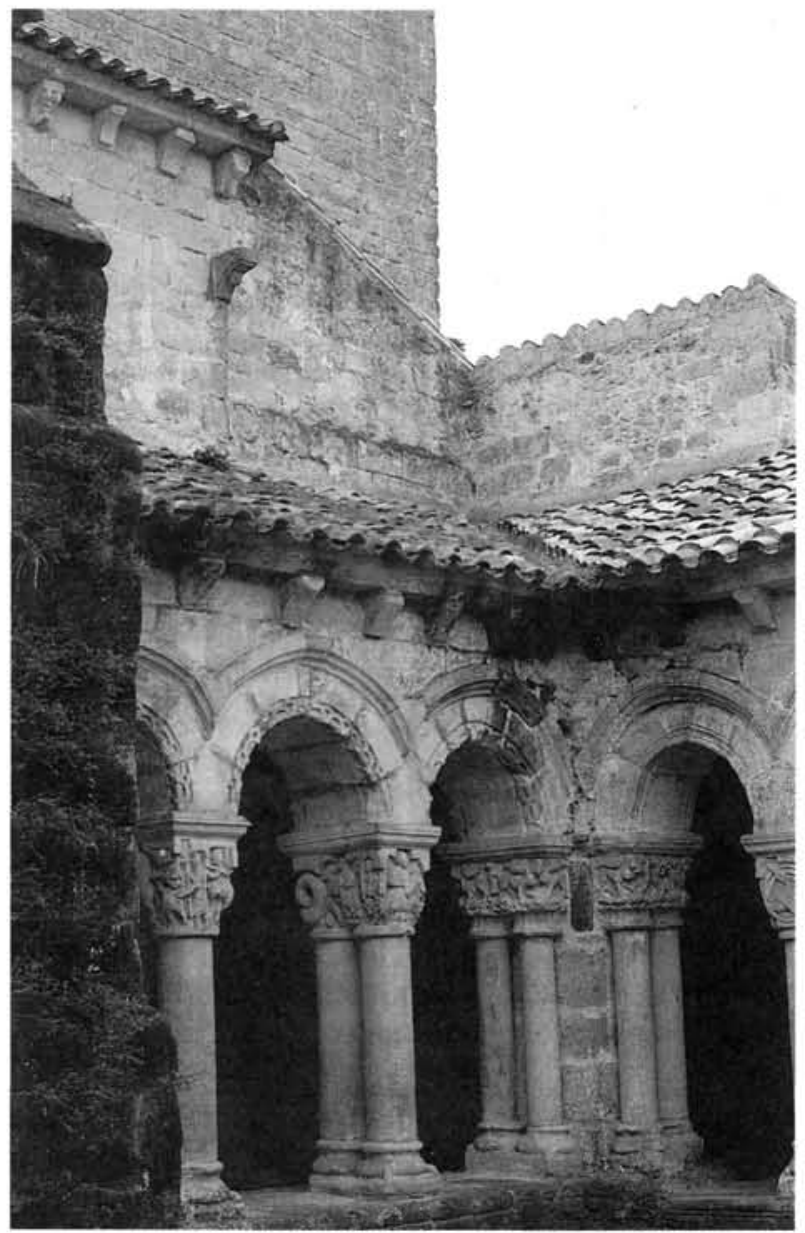

Ángulo del Claustro más dañado por el agua.-Este aspecto ofrecía el ángulo del Claustro donde se producia más deterioro debido al de. sastroso estado de las cubiertas.

El problema no era nuevo. En las fotos antiguas se comprueba que esa esquina del Claustro estaba macizada con un murete, porque los fustes se habian deshecho con la humedad. 


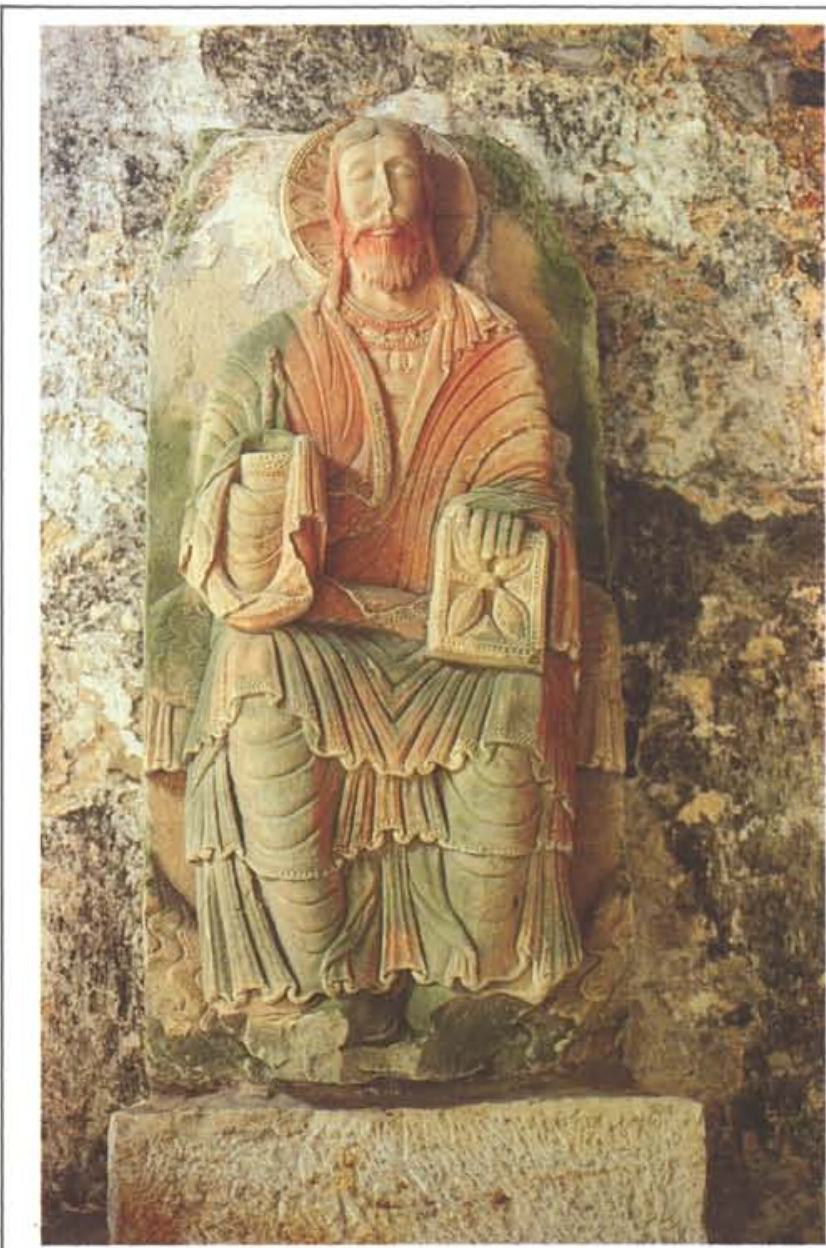

Policromia falsa del pantocrator debida a daños bióticos. - La colo. ración verde de este magnifico relieve, que probablemente estuvo en la primitiva fachada principal de la Colegiata, se debe a cianofitos.

\section{RESTAURACIÓN DE CUBIERTAS}

Naves laterales. Dado que la estructura de madera de las últimas restauraciones estaba completamente deteriorada, salvo el falso techo, se optó por utilizar un sistema de estructura con materiales modernos adecuados a estas circunstancias concretas.

Con objeto de evitar movimientos y empujes de la cubierta hacia el interior del Claustro se construyó, en las tres galerias bajas, un zuncho perimetral de hormigón armado que se absorbia con el leve recrecido de la cornisa, viguetas de hormigón y bovedillas de poliestireno expandido de alta densidad, capa de compresión con malla electrosoldada impermeabilizante y capa de compresión para el agarre de la teja árabe. Los pesebrones se construyeron en plomo y sin canalones. El

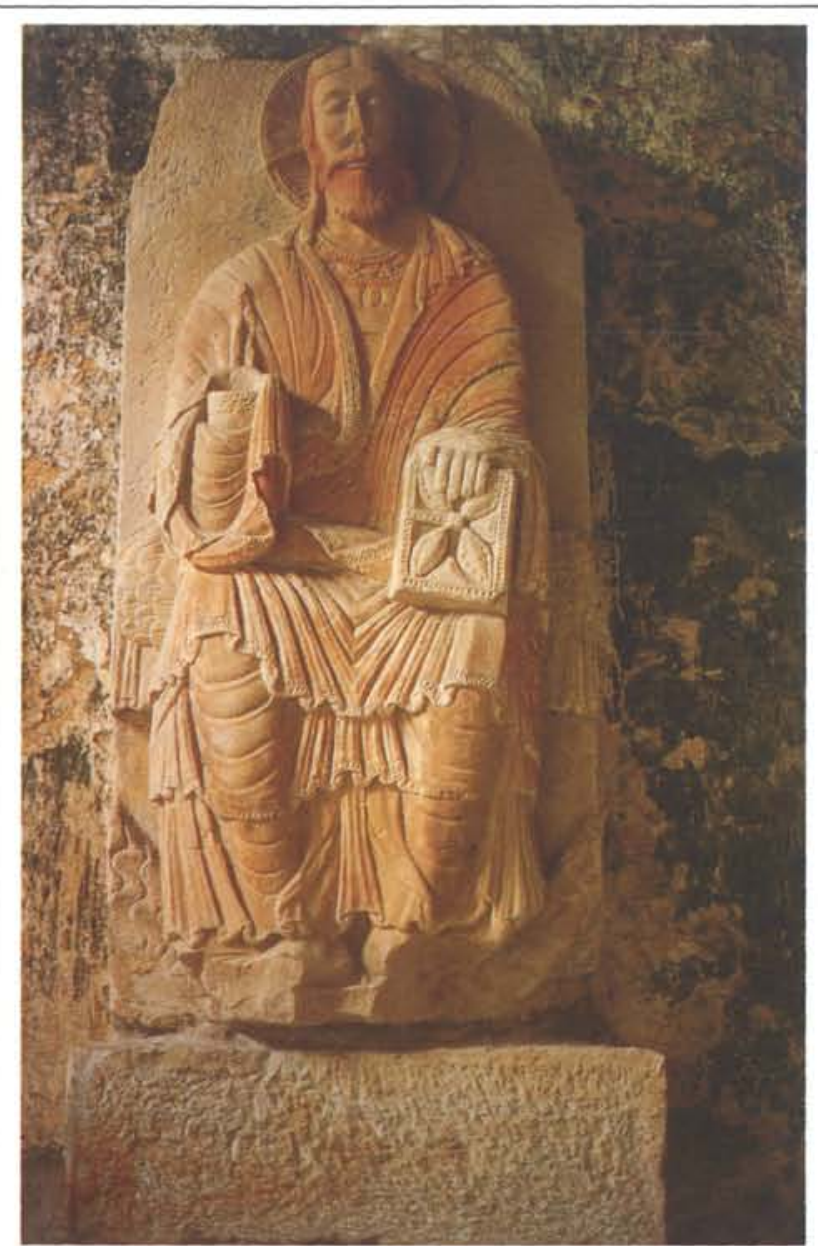

Pantocrator en su estado actual. - Una vez desaparecidas las algas, la piedra conserva el color natural, con sus diferentes coloraciones rojizas y sin perjudicar la posible acentuación de esos tonos que realzan más la figura.

El tratamiento tan sólo afectó a las algas como se comprobó unos meses después al tener eflorescencias en las zonas que antes estaban de color verde, es decir, las hifas secas de las algas, con aspecto ligeramente gelatinoso que no debe confundirse con el aspecto que presentan a veces piedras tratadas con resinas cuando éstas se alte. ran por la humedad que aún conserva la piedra. agua que recogen otras cubiertas, que se orientan hacia el Claustro, hace años se había canalizado con canalones de cobre.

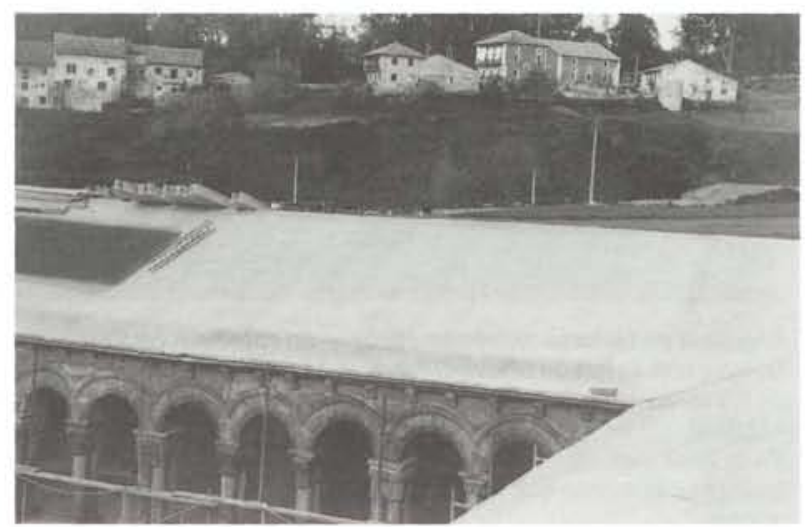




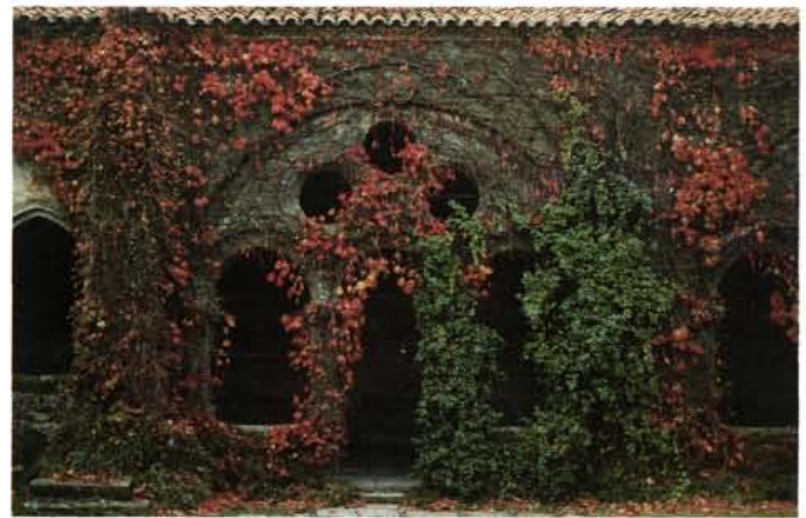

Vegetación existente. - Consideramos que es bueno mantener la imagen que ha marcado a un monumento durante un tiempo considera ble. En nuestro caso formaba parte de esa imagen -y se ha llevado miles de fotografias - la hiedra que cubre la galería moderna del Claustro.

Tanto en las obras de drenaje como en las de cubiertas tuvimos buen cuidado de protegerla para que siguiera cumpliendo una misión que no era incompatible, en absoluto, con el resto del ajardinamiento. Sus cambios exóticos de colorido forman parte integrante de los valores estéticos del Claustro, como ocurre en Silos con el ciprés, aunque sólo tenga cien años.

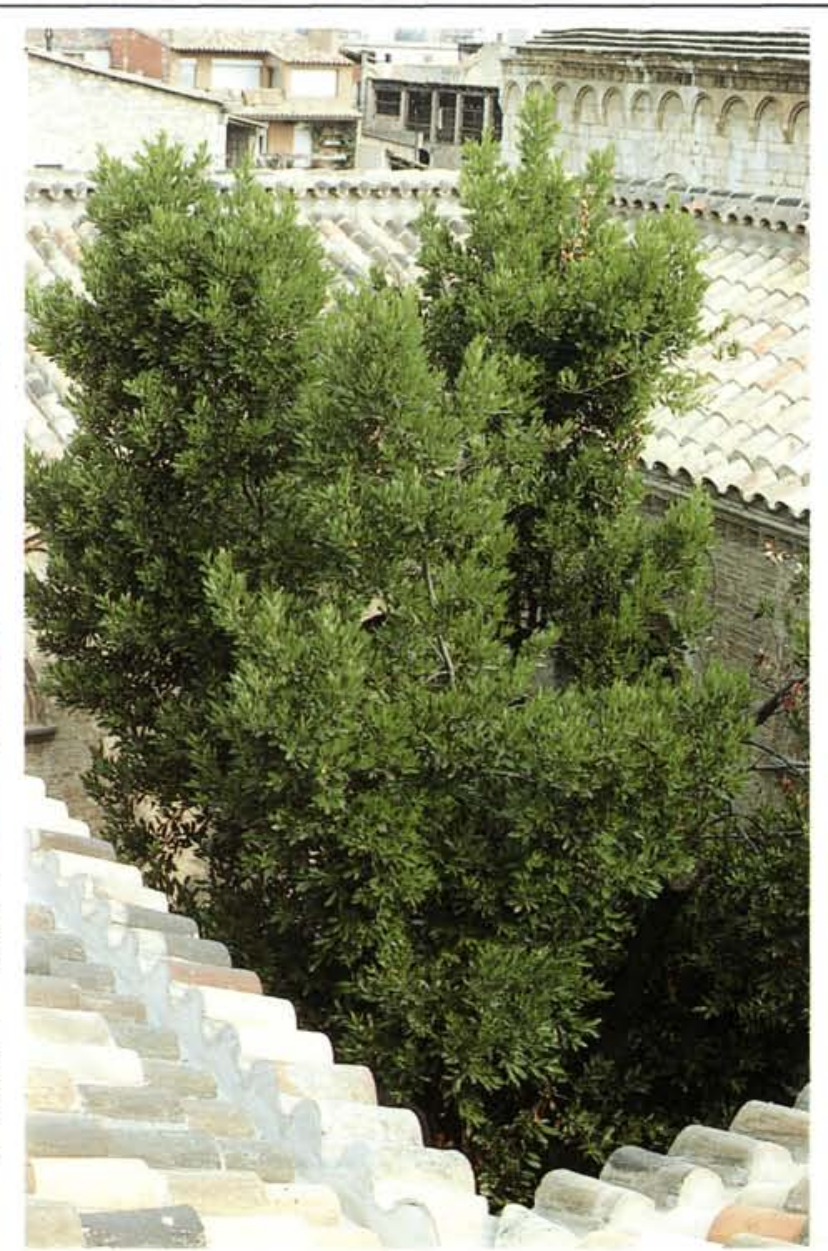

San Pere de Galligans (Gerona). - Este Claustro de San Pere de Galligans se adosó a la iglesia a mediados del siglo XII. En el XIX se recre. ció con otra planta donde se instaló el Museo Arqueológico. Natural. mente, variaron sus condiciones climáticas, ya que, siendo de reducidas dimensiones, con otra planta resultaba excesivamente sombrio. A ello se añade que la vegetación existente, que se reduce más bien a un árbol, ha ido creciendo hasta llegar a los limites en que estaba, al menos, hace 7 años.

El resultado es una pérdida de luminosidad, casi total, y exceso de humedad. Tal vez incluso las raices pueden dañar el subsuelo arqueo. lógico y el basamento del mismo Claustro.
En lo que se refiere a la cubierta de la galeria alta, simplemente se repuso toda la tabla, tratada previamente contra xilófagos. Sobre ella se clavó tablero hidrófugo DMH de $10 \mathrm{~mm}$ en planchas grandes - también tratado - y luego capa de compresión armada, por lo que el aspecto desde el interior sigue siendo el mismo:

- falso techo de roble y castaño en galerías románicas;

- estructura de madera vista - también de roble y castaño- para el caso de la otra galería.

\section{ESTUDIO DE LAS CONDICIONES CLIMÁTICAS DEL CLAUSTRO PARA SU AJARDINAMIENTO}

Solucionados los problemas de drenaje y cubiertas se

(c) Consejo Superior de Investigaciones Científicas

Licencia Creative Commons 3.0 España (by-nc) nos ofrecia una ocasión oportuna de ajardinar el Claustro. Con ello queriamos cumplir varios objetivos que no se señalan en orden de importancia:

1) Recuperar la imagen que pudo tener el Claustro en otros tiempos pasados.

2) Mejorar el microclima del Claustro en cuanto a una mayor aireación del subsuelo, debido a la evaporación de humedad que producen las plantas.

3) Completar un aspecto cultural del monumento como es el hecho de que durante varios siglos los monasterios dispusieron de magnificas boticas donde se elaboraban las medicinas, en base a las plantas medicinales que cultivaban en la huerta y en los claustros. 


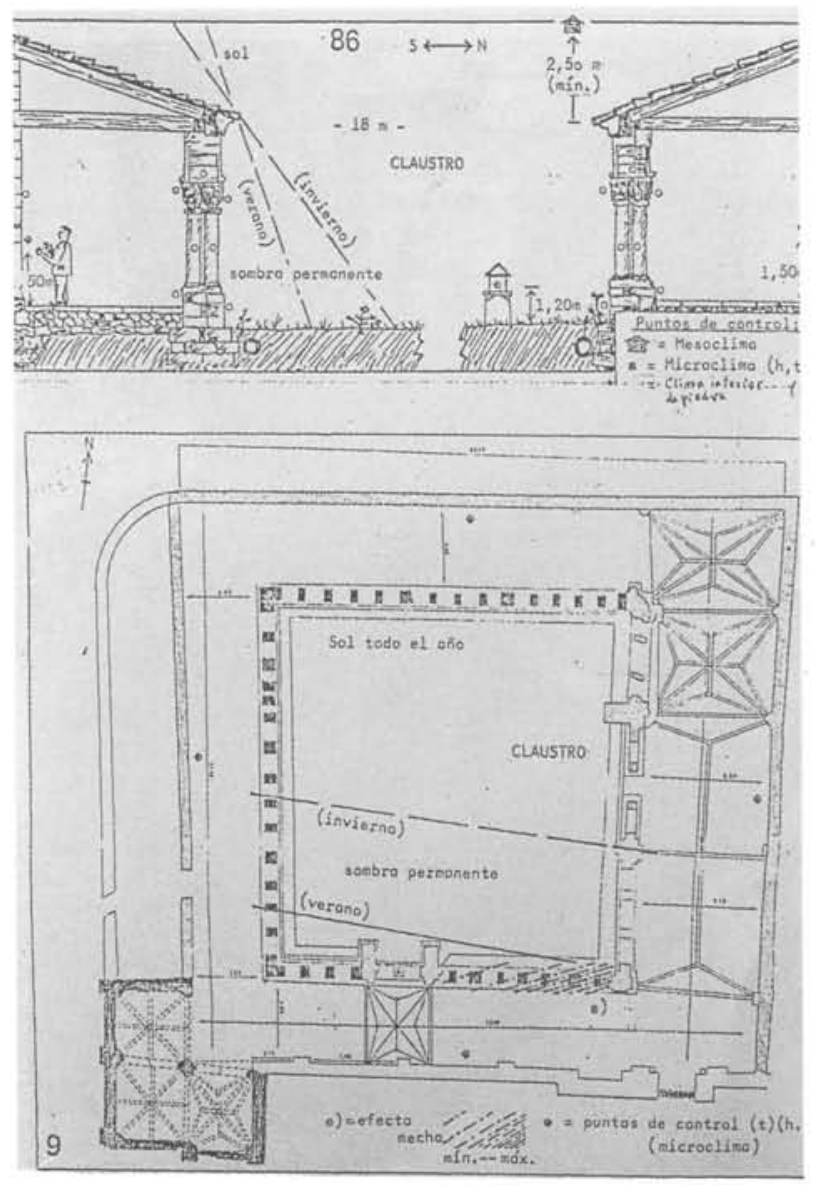

G. Kraemer

Para ello se analizaron las condiciones climáticas del Claustro de Santillana y se estudiaron las plantas que podrian constituir su ajardinamiento. Quedaba el criterio estricto a seguir en la elección de plantas y arbustos, por ejemplo exclusivamente plantas conocidas antes del descubrimiento de América, o bien completar con todas éstas. Consultando con expertos, como el restaurador del Jardín Botánico de Madrid, don Leandro Silva o el Ingeniero-Jefe de conservación de Jardines del Patrimonio Nacional, don Carlos Herránz, decidimos utilizar mayoritariamente la lista de plantas medicinales y de adorno clásicas en la Edad Media, pero introduciendo también algunas más recientes. Quizás así se producia una correlación con la arquitectura del monumento que, siendo en su estructura románica, también tuvo adiciones góticas y de época reciente.

\section{LA SOLUCIÓN ELEGIDA PARA EL CLAUSTRO DE SANTILLANA DEL MAR}

En la escasa bibliografia existente sobre el ajardinamiento de claustros medievales hemos encontrado referencias inequívocas de su aspecto ajardinado. En croquis y dibujos antiguos, como por ejemplo de Einsiedeln en Suiza y Sant Gallen, vemos jardines medicinales y divisiones sistemáticas en parterres. En la inmen- sa mayoria de los claustros aún se mantiene la tradicional división en dos ejes, con todo lo que lleva implícito de simbología referida al jardín del Edén y a los ríos Tigris y Eúfrates.

Dado que en el siglo pasado se removió casi todo el recinto del Claustro de Santillana hasta una profundidad de casi dos metros no es posible averiguar si tuvo estos ejes, si hubo fuente o lavatorio - tal vez algún pozo- y cuál pudo ser su emplazamiento.

Por todo ello, aunque hubiera sido defendible instalar una fuente o pozo hemos preferido no instalarlo, aunque si dar alguna referencia como los ejes y la división en parterres, cuidando de que todo ello sea reversible sin perjuicio para el monumento.

\section{ESQUEMA DE AJARDINAMIENTO EN EL CLAUSTRO DE SANTILLANA DEL MAR}

De acuerdo con la irregular traza del Claustro los ejes van sensiblemente formando dos ejes centrados. La en. trada nos coincide con la que ya tenía a través de la galeria reconstruida en el siglo XIX, que suponemos coincide con la entrada antigua, ya que está en el paso de comunicación entre la iglesia y las habitaciones que ocuparon primero los monjes y luego los clérigos.

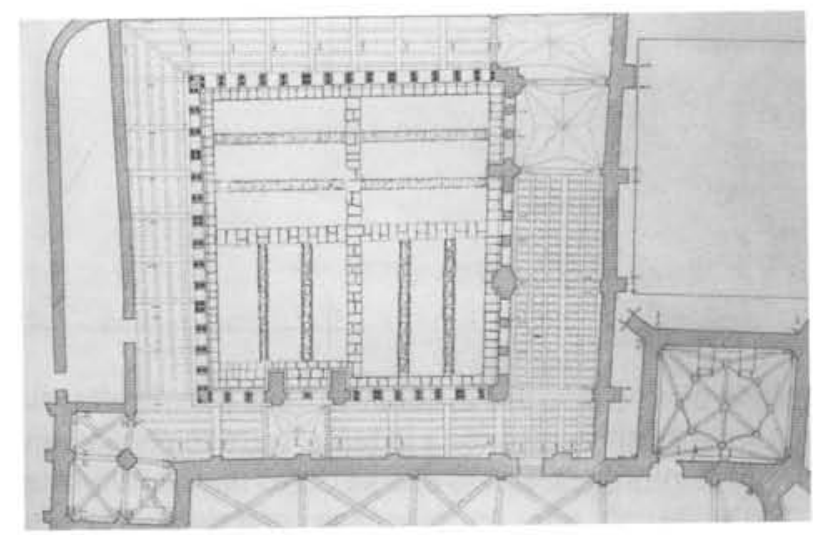

En lo que se refiere a los parterres es una division puramente convencional y fácilmente variable, pues lleva simplemente piedras grandes de rio, alargadas y planas, buscadas al efecto, que van clavadas en la tierra. Entre los parterres lleva un simple paso de pequeñas losas de piedra natural, tampoco asentadas con mortero sino directamente sobre la tierra, por lo que, al igual que entre las piedras de los ejes principales, puede crecer la hierba.

De esta forma, si por un motivo razonable conviene cambiar la disposición, no se produce ninguna altera. ción. 


\section{COLOCACIÓN DE LAS PLANTAS SEGÚN CONDICIONES CLIMÁTICAS DEL CLAUSTRO}

Según las diferentes condiciones climáticas de los parterrres se distribuyen las plantas de sol o de sombra, con más o menos agua, condicionados por la restauración del drenaje del siglo XIX que dejó poco espesor de tierra superficial.

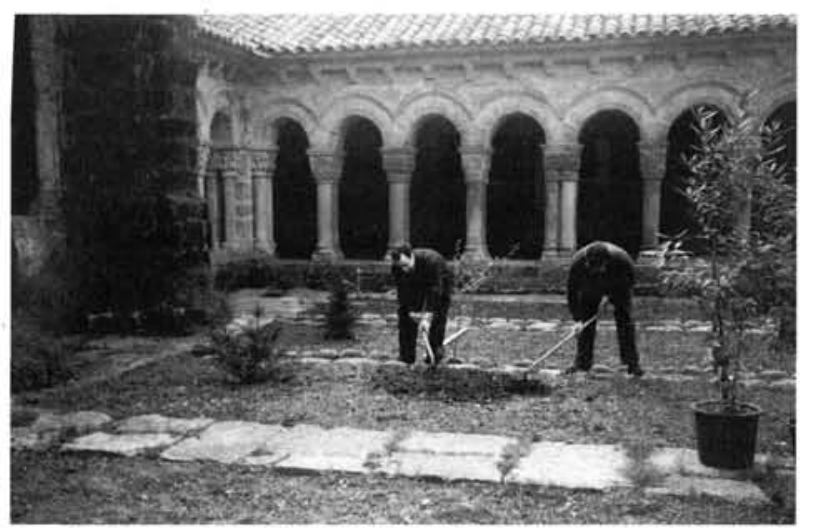

En cada cuadrante se ha previsto la colocación de tablillas de castaño preparadas para intemperie, donde lleva incisos por pirograbado el nombre en latín y vulgar de cada planta y sus condiciones más relevantes, junto con un número de referencia que puede consul. tarse con más amplitud en paneles grandes que decoran una pared con revoco. (Ver anexo, página 21).

Con estos paneles se pretende completar, en plan didáctico, el carácter de las plantas, lo que complementa la visita al monumento con esta nueva faceta cultural.

Hemos querido facilitar al máximo el trabajo de mantenimiento con una instalación de riego automático, que también nos permitirá controlar mejor la humedad ambiental y el microclima del Claustro. Se ha previsto de modo que el agua nunca pueda mojar directamente ni siquiera el zócalo en que se asientan las galerias románicas.

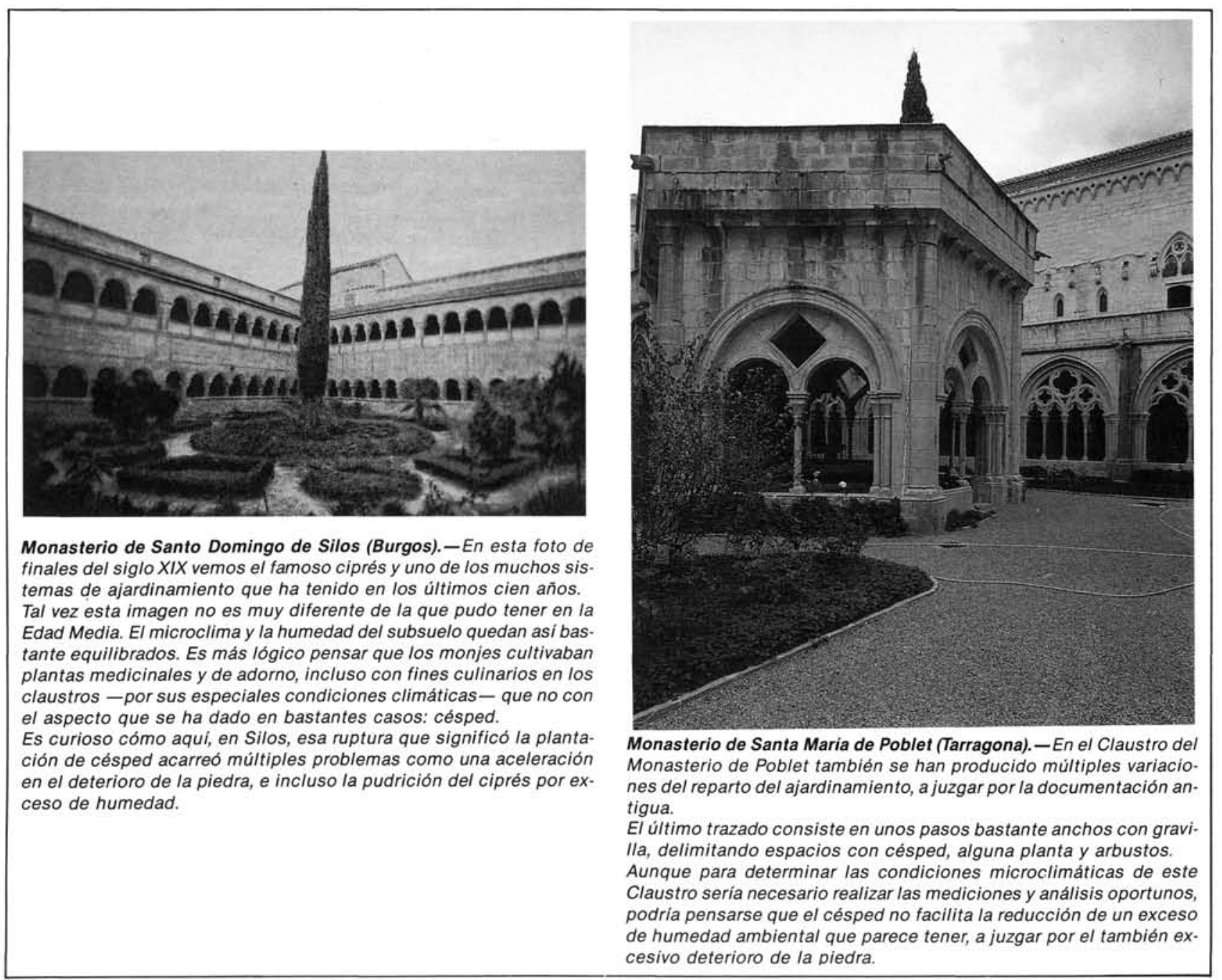




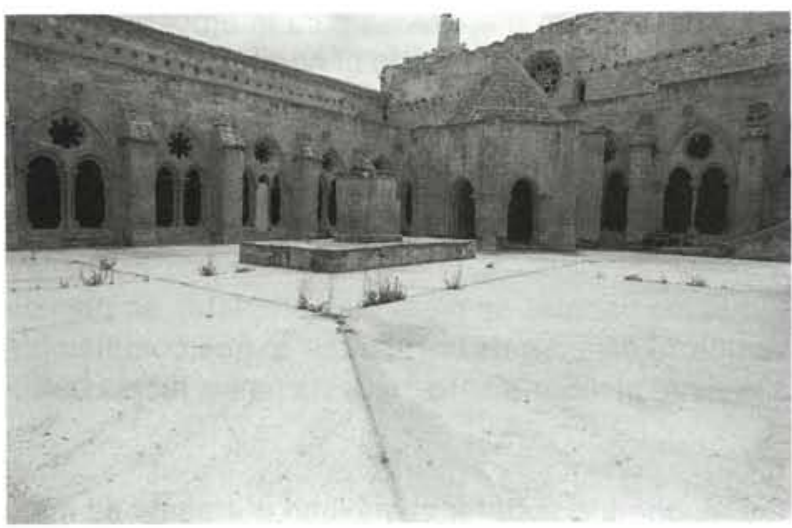

Monasterio de Rueda en Escatrón (Zaragoza). - Cerca de Escatrón se conservan los restos del Monasterio de Rueda, de gran importancia monumental, pero sin uso, que es casi lo mismo que decir abando. nado.

En alguna restauración, que parece reciente, se ha hormigonado todo el recinto del claustro gótico, 10 cual se considera inadecuado.

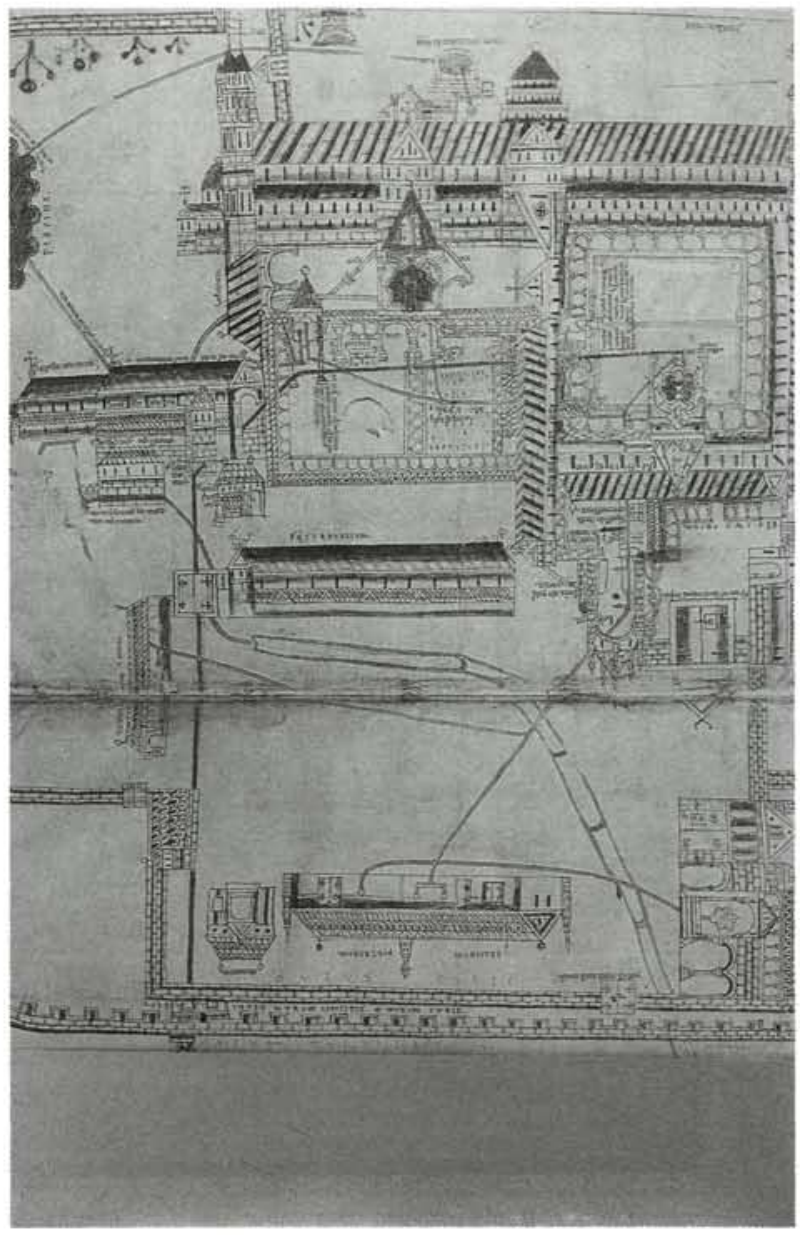

El Claustro Benedictino de Cantorbery.-Documento original en el Trinity College de Cambridge. Se trata de un croquis del siglo XII, con el sistema proyectado de conducción de agua a todo el Monasterio. Se han reproducido con bastante ingenio, en cuanto al sistema de proyección abatida, todos los diferentes edificios del complejo mo nástico. En la parte superior está la iglesia con dos claustros adosa. dos; en uno de ellos está rotulado "herbarium". Un sistema de riego, que podemos casi calificar de automático, distribuye el agua a las fuentes y diversas dependencias; están también señaladas las lineas de drenaje.

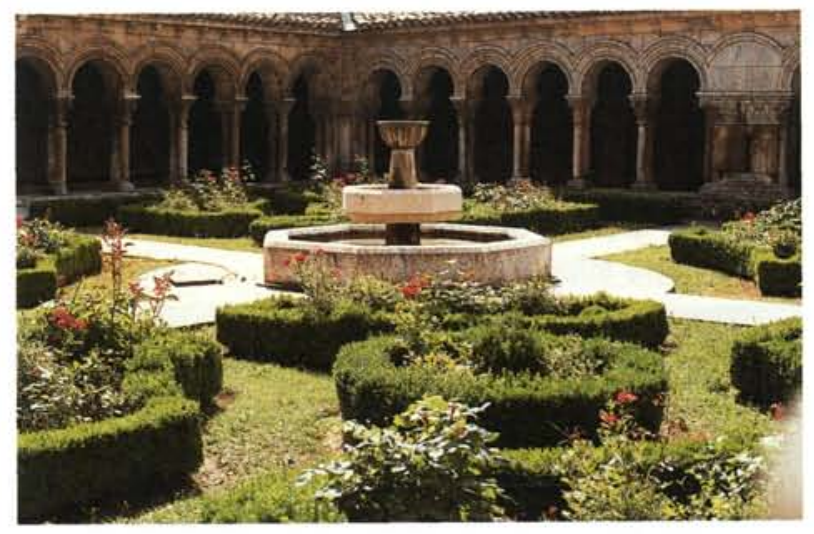

El Monasterio de las Huelgas (Burgos). - Aqui tenemos un ejemplo interesante de claustro tradicional: los dos ejes, la fuente centrada y la división en parterres para el cultivo de plantas diferenciadas. Resulta curioso comprobar que en este caso no existe un deterioro desproporcionado de la piedra, tal vez porque se ha mantenido un equilibrio en su microclima mediante este ajardinamiento que es perfectamente válido y sigue cumpliendo su misión de agradar la vista y proporcionar flores de ornato con las que adornar la iglesia y otras zonas del Monasterio.

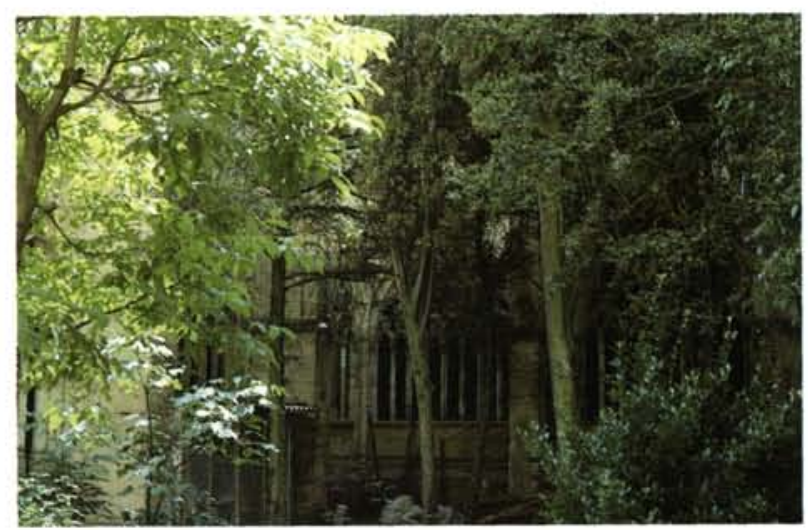

El Claustro de la Catedral de Segovia.-Exceso de vegetación y des. proporción del tamaño de su arbolado.

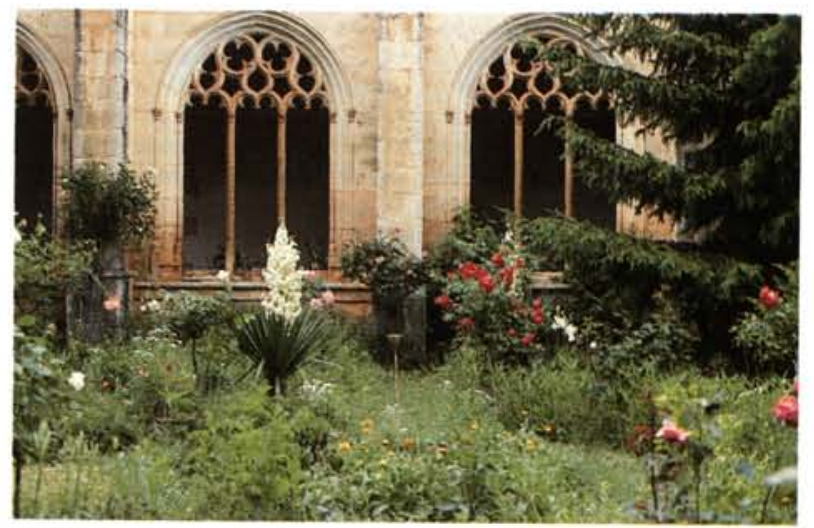

El Claustro de la Colegiata de Covarrubias (Burgos). - Ejemplo de ajardinamiento al que se ha llegado por el sentido común, el buen gusto y espiritu de trabajo de quienes 10 conservan. 


\section{ANEXO}

Propuesta del Dr. KRAEMER para la plantación

\section{Arbustos}

Aquí cabe prácticamente todo lo que da flor y es decorativo. A título informativo citamos algunos arbustos que conocemos como típicos para la región.

Las especies de arbustos decorativos que serían correctos son:

Cornus mas.

Evonymus europeus, o especies cultivadas.

Jasminum nudiflorum (arbusto trepador usado como Lonicera).

Laburnum anagyroides (muy bonito, pero muy tóxico).

Ligustrum vulgaris.

Lonicera species (arbusto trepador usado especialmente en rincones que se usaban para poner algún banco, etcétera).

Mirabilis jalapa (la flor del milagro, la tenía el claustro de la catedral y no debe faltar; es también planta medicinal y

Sambucus niger. famosa por ser el medio de los ensayos de Méndel).

Sorbus aucuparia.

Symphoricarpus albus.

Syringa vulgaris.

Virburnus opulus, V. lantarum.

\section{Especias}

Se pueden plantar todas de las corrientes, como romero, comino, tomillo, eneldo, etcétera.

\section{Plantas medicinales}

Éste es un extenso capítulo y las especies varian mucho. En vista de que aqui deseamos obtener una comprensión óptica del conjunto, no un jardín científico, se pueden plantar cualquiera de las especies que son frecuentes en la Zona Norte y sirven para la zona de sol. En posición de semisombra conviene plantar algunos Ricinus, especies que suelen alcanzar unos 2-3 metros de altura y son muy decorativos. Casi siempre han estado presentes en las plantaciones medicinales del norte.

\section{Plantas trepadoras}

La tipica trepadora de las zonas del norte son especies de Wistaria que, asoleadas, ofrecen en primavera sus suaves flores, grandes y decorativas. Para florecer durante todo el año se tienen las especies de Convólvulus que hay en muchísimas variaciones y colores. No obstante, son algo incorrectas; lo que plantaron ha sido lpomoea purpúrea que venia de Sudamérica y, como alimento y decoración, Ipomoea batatas, de México.

En este punto de las trepadoras también seria correcto un limonero, si el sitio es suficientemente protegido.

\section{Verduras}

Ha sido objeto de muchos estudios qué verduras se plantaron en los antiguos cultivos de los monasterios y la variación regional es la mayor de todos los cultivos que habia entonces. En nuestro caso naturalmente no deseamos que se plante lechuga y tomate, sino buscar plantas más raras de cierto efecto decorativo (por ejemplo, alcachofas) y que son conocidas como cultivadas en la región. En situación de más o menos sombra se debia dedicar cierta parte a un cultivo de Rheum, del que no solamente se comian las hojas dulces, también se usaban las raíces como medicamento.

En posición soleada siempre había Cucumis sativus (pepino) que con frecuencia se dejó crecer dentro de botellas que luego se llenó con orujo para obtener un medicamento (algo embrujado).

También naturalmente había siempre Curcubita, la especie $C$. máxima por su llamativo tamaño valía en nuestro caso, o Citrullus vulgaris (melón de agua). Cucumis melo (melón) para Navarra no sería típica dentro de los claustros, se cultivaba en el campo.

\section{Flores}

Tanto en posición de sol como en zonas de sombra valen en nuestro caso todo lo que en Navarra es corriente. Poner bordes de Buxus, no es correcto para Cantabria, sino típico para el centro de España. Entre las plantas de flores mayores, especialmente cerca del pozo, han sido frecuentes toda clase de lilias. Debajo de los árboles frutales frecuentaron Crocus vernis $u$ otras especies.

Además vale aquí cualquier flor decorativa o rara para poner en forma destacada.

Entre los rosales se debian usar tipos de flores pobres, casi de aspecto salvaje. Existen hoy variaciones que disimulan este tipo entre los rosales enanos, pero florecen todo el año y en muchos colores. A esta zona, de los rosales, pertenecia también Lunaria annua ("gafas del Santo Padre") que como curiosidad italiana se cultivaba con frecuencia en los claustros. 